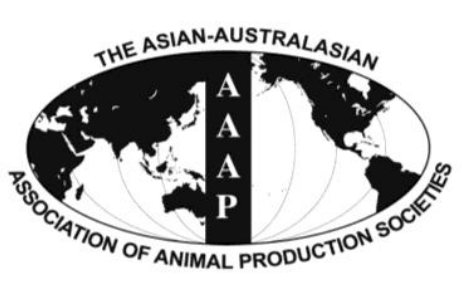

\begin{tabular}{c} 
Open Access \\
Asian Australas. J. Anim. Sci. \\
$\begin{array}{c}\text { Vol. 27, No. } 2: \text { 155-160 February 2014 } \\
\text { http:/dx.doi.org/10.5713/ajas.2013.13430 }\end{array}$ \\
\hline www.ajas.info \\
pISSN 101 1-2367 elSSN 1976-5517
\end{tabular}

\title{
Estimation of Genetic Parameters for Real-time Ultrasound Measurements for Hanwoo Cows at Different Ages and Pregnancy Status
}

\author{
J. H. Lee ${ }^{\text {a }}$, Y. M. Lee ${ }^{1, a}$, S.-H. Oh ${ }^{2, a}$, H. J. Son ${ }^{3}$, D. J. Jeong ${ }^{3}$, Niki Whitley ${ }^{2}$, and J. J. Kim ${ }^{1, *}$ \\ Gyeongbuk Provincial College, Yecheon, Gyeongbuk, Korea
}

\begin{abstract}
The purpose of this study was to estimate genetic parameters of ultrasound measurements for longissimus dorsi muscle area (LMA), backfat thickness (BFT), and marbling score (MS) in Hanwoo cows ( $=3,062$ ) at the ages between 18 and 42 months. Data were collected from 100 Hanwoo breeding farms in Gyeongbuk province, Korea, in 2007 and 2008. The cows were classified into four different age groups, i.e. 18 to 22 months (the first pregnancy period), 23 to 27 (the first parturition), 28 to 32 (the second pregnancy), and 33 to 42 (the second parturition), respectively. For each age group, a multi-trait animal model was used to estimate variance components and heritabilities of the three traits. The averages of LMA, BFT, and MS measurements across the cows of all age groups were $50.1 \mathrm{~cm}^{2}, 4.62 \mathrm{~mm}$, and 3.04 , respectively and heritability estimates were $0.09,0.10$, and 0.08 for the respective traits. However, when the data were analyzed in different age groups, heritability estimates of LMA and BFT were 0.24 and 0.47 , respectively, for the cows of 18 to 22 months of age, and 0.21 for MS in the 28 to 32 months old cows. When the cows of all age groups were used, the estimates of genetic (phenotypic) correlations were $0.43(0.35),-0.06(0.34)$ and $0.21(0.32)$ between LMA and BFT, LMA and MS, and BFT and MS, respectively. However, in the cow age group between 28 and 32 (18 and 22) months, the estimates of genetic (phenotypic) correlations were $0.05(0.29),-0.15(0.24)$ and $0.38(0.24)$, for the respective pairs of traits. These results suggest that genetic, environmental, and phenotypic variations differ depending on cow age, such that care must be taken when ultrasound measurements are applied to selection of cows for meat quality. (Key Words: Real-time Ultrasound, Heritability, Cows, Hanwoo)
\end{abstract}

\section{INTRODUCTION}

Real-time ultrasound measurement is a technology for early evaluation of meat quality without carcass processing (Ludwig, 1950; Howry and Bliss, 1952). Temple et al. (1956) measured subcutaneous fat using A-mode (amplitude modulation) at the first stage of ultrasound measurement, followed by the use of B-mode (bright modulation) in 1968. However, the two types of

\footnotetext{
* Corresponding Author: Jong-Joo Kim. Tel: +82-53-810-3027, Fax: +82-53-801-3027, E-mail: kimjj@ynu.ac.kr

${ }^{1}$ School of Biotechnology Yeungnam University, Gyeongsan, Gyeongbuk, Korea.

2 Department of Animal Sciences, North Carolina A\&T State University, Greensboro, NC 27411, USA.

${ }^{3}$ Gyeongbuk Livestock Research Institute, Yeongju, Gyeongbuk, Korea.

${ }^{\text {a }}$ The authors contributed equally to this work.

Submitted Jul. 17, 2013; Accepted Oct. 8, 2013; Revised Nov. 1, 2013
}

measurements did not enable well definition of lipid and muscle in the meat tissues.

A more practical application of real time ultrasound was reported by Waldner et al. (1992), in which longissimus dorsi muscle area (LMA) and backfat thickness (BFT) were measured in Brangus bulls at 4 to 24 months of age. There were other reports in which ultrasound measurements were used to predict carcass quality traits before slaughtering (Perkins et al., 1992; Herring et al., 1998). Since 1990, the application of ultrasound measurements were extended to estimate genetic parameters for young bulls and heifers, so as to reduce time and cost for progeny testing (Shepard et al., 1996; Moser et al., 1998; Reverter et al., 2000; Crews et al., 2002; Stelzleni et al., 2002; Crews et al., 2004; Pinheiro et al., 2011).

There were several studies about repetitive ultrasound measurements for genetic parameter estimation (Hassen et al., 1999; Hassen et al., 2004; Pinheiro et al., 2011). Hassen et al. (1999) reported that standard errors of the estimates of

Copyright $@ 2014$ by Asian-Australasian Journal of Animal Sciences This is an open-access article distributed under the terms of the Creative Commons Attribution Non-Commercial License (http://creativecommons.org/licenses/by-nc/3.0/), which permits unrestricted non-commercial use, distribution, and reproduction in any medium, provided the original work is properly cited. 
intramuscular fat decreased as the number of repetitive measurement increased, e.g. from the 1 st to the 6 th times. Hougton and Turlington (1992) pointed out that adjustments for ultrasound equipment and protocol as well as breed, age and body weight of animals had to be made to obtain accurate estimates. The most common cattle breeds for which ultrasound has been used are Angus, Brangus, Hereford, and Simmental, of which young bulls and heifers were used for genetic parameter estimation of LMA, BFT and marbling score (MS). Hassen et al. (2004) reported that the most appropriate age for ultrasound measurements was 12 months in Angus, and when animals were used that were younger than 320 days or older than 410 days, the estimates had less accuracy (BIF, 1996).

Heritability estimates of LMA, BFT, and intramuscular fat $(\%)$ have been reported in the range of 0.11 to $0.61,0.11$ to 0.69 , and 0.16 to 0.52 , respectively (Shepard et al., 1996; Moser et al., 1998; Hassen et al., 1999; Reverter et al., 2000; Crews et al., 2002; Stelzleni et al., 2002; Crews et al., 2004; Hassen et al., 2004; Pinheiro et al., 2011).

Roh et al. (2010) reported that heritabilities for ultrasound measured LMA, BFT and MS in Hanwoo cattle were estimated to be $0.57,0.41$, and 0.14 at 12 months of age, and $0.57,0.60$, and 0.22 at 24 months of age, respectively, in performance testing bulls and progeny testing steers. In a Hanwoo cow population in which the cows were older than 18 months of age, heritability estimates using ultrasound measurements were 0.14 to 0.39 , 0.19 to 0.48 , and 0.13 to 0.38 for LMA, BFT, and MS, respectively, in Koo (2007), Yoon (2010) and Choy et al. (2011). However, in their reports, the genetic parameters for the ultrasound measures were not estimated in homogeneous age groups, i.e. the age of the cows in the samples varied between 18 and 60 months.

The purpose of this study, therefore, was to estimate genetic parameters of ultrasound measurements at various age groups in an effort to better understand genetic variability at different ages in a Hanwoo cow population.

\section{MATERIALS AND METHODS}

\section{Animals and phenotype data}

The Hanwoo cows that were used in this study were born between 2000 and 2007, and were between the ages of 12 and 42 months. The ultrasound measurement data were collected from 100 Hanwoo commercial farms in Gyeongbuk province in 2007 and 2008, mainly by one trained technician. The cows were classified into four different age groups, i.e. the first pregnancy period (683 cows between 18 and 22 months), the first parturition period (794 between 23 and 27), the second pregnancy period ( 861 between 28 and 32), and the second parturition period (724 between 33 and 42). The ultrasound traits were longissimus dorsi muscle area $\left(\mathrm{cm}^{2}\right.$; LMA), backfat thickness (mm; BFT), and marbling score (MS), which were measured between the 13th rib and 1st lumbar vertebrae with a Medicine (Ltd.) Pico v103 instrument (cm, 3.5 MHz linear array probe). The MS was scored from the ultrasound image by eye, as one through nine according to the Korean Beef Marbling Standard $(1=$ trace, $9=$ very abundant). Body condition scores were also measured as levels 1 through 5 at the same time of measuring the ultrasound traits.

\section{Statistical model}

A multi-trait animal model was used for genetic parameter estimation of the ultrasound measures;

$$
\mathrm{Y}=\mu+B y s+T y s+L F+B C S+a g e+a+e
$$

Where, $\mathrm{Y}$ is a dependent variable, the measurement of each trait, $\mu$ is overall mean, Bys is a fixed effect of birth year and season (28 levels), Tys is a fixed effect of year and season (eight levels), $L F$ is a fixed effect of farm (100 levels), $B C S$ is a fixed effect of body condition score (five levels), age is a covariate of months of age, $a$ is a random effect of additive genetic effect of each individual, and $e$ is a random effect of random error. Estimation of variance components were based on a multi-trait animal model using REML method with ASREML program (Gilmour et al., 1999), across all ages or for each age group of cows.

\section{RESULTS AND DISCUSSION}

Statistics for real-time ultrasound and body condition score measurements in Hanwoo cows are shown in Table 1 and Figure 1. There were increasing trends in the measurement of the ultrasound traits during the first pregnancy period (18 to 22 months of age), decreasing in the parturition period ( 23 to 27 months of age), increasing in the second pregnancy ( 28 to 32 months), and decreasing in the second parturition periods (33 to 37 months of age). Because lactation requires a great amount of energy, it is commonly known that BFT accretion decreases at the parturition times, in which primiparous cows under the strain of both body growth and the first lactation may be exposed to reduction of muscling. The averages of ultrasound measures for the cows across all age groups were $50.1 \mathrm{~cm}^{2}, 4.62 \mathrm{~mm}$, and 3.04 for LMA, BFT, and MS, respectively. The averages in the first and the second pregnancy periods were $49.7 \mathrm{~cm}^{2}$ and $50.2 \mathrm{~cm}^{2}, 4.51 \mathrm{~mm}$ and $4.69 \mathrm{~mm}$, and 2.48 and 3.42 , for the respective traits, which was in general agreement with the fact that LMA or fat deposition increase with age. Increments of muscling and fat deposition with age were also observed in Japanese Black as well as European cattle breeds (Gotoh et al., 2009). 
Table 1. Statistics for real-time ultrasound and body condition score measurements in Hanwoo cows of different age groups and pregnancy status

\begin{tabular}{|c|c|c|c|c|c|c|}
\hline Trait & Age (mean of month) & $\mathrm{N}$ & Mean & Std & Min & Max \\
\hline \multirow[t]{5}{*}{$\operatorname{LMA}\left(\mathrm{cm}^{2}\right)$} & $18-22(20.6)$ & 683 & 49.7 & 6.46 & 33 & 72 \\
\hline & $23-27(25.2)$ & 794 & 49.1 & 7.12 & 30 & 85 \\
\hline & $28-32(29.8)$ & 861 & 50.2 & 7.65 & 31 & 76 \\
\hline & $33-42(37.6)$ & 724 & 51.6 & 7.70 & 29 & 82 \\
\hline & Overall (28.4) & 3,062 & 50.1 & 7.33 & 29 & 85 \\
\hline \multirow[t]{5}{*}{ BFT (mm) } & $18-22(20.6)$ & 683 & 4.51 & 1.74 & 1 & 12 \\
\hline & $23-27(25.2)$ & 794 & 4.31 & 2.00 & 1 & 13 \\
\hline & $28-32(29.8)$ & 861 & 4.69 & 2.31 & 1 & 15 \\
\hline & $33-42(37.6)$ & 724 & 4.99 & 2.60 & 1 & 16 \\
\hline & Overall (28.4) & 3,062 & 4.62 & 2.20 & 1 & 16 \\
\hline \multirow[t]{5}{*}{ MS } & $18-22(20.6)$ & 683 & 2.48 & 1.83 & 1 & 14 \\
\hline & $23-27(25.2)$ & 794 & 2.95 & 2.01 & 1 & 18 \\
\hline & $28-32(29.8)$ & 861 & 3.42 & 2.48 & 1 & 18 \\
\hline & $33-42(37.6)$ & 724 & 3.21 & 2.55 & 1 & 22 \\
\hline & Overall (28.4) & 3,062 & 3.04 & 2.27 & 1 & 22 \\
\hline
\end{tabular}

LMA = Longissimus dorsi muscle area, BFT = Backfat thickness, MS = Marbling score (1 to 9).

There are several reports about ultrasound measurements in beef cattle, in which breed, age and sex influenced muscle and fat deposition (Zhou et al., 2001; Yokoo et al., 2006; Gotoh et al., 2009). Crews et al. (2004) reported that ultrasound measurements for LMA, BFT and intramuscular fat $(\%)$ were $66.1 \mathrm{~cm}^{2}, 3.94 \mathrm{~mm}$, and 3.40 , respectively, in Simmental heifers at 12 months of age. Robert et al. (2007) reported $58.8 \mathrm{~cm}^{2}, 3.96 \mathrm{~mm}$, and 3.52 for the respective traits in 1/2 red Angus, 1/4 Charolais, and 1/4 Tarentaise heifers of 12 months of age. Pinheiro et al. (2011) reported $47.5 \mathrm{~cm}^{2}$ and $1.34 \mathrm{~mm}$ for LMA and BFT in Nelore bulls and heifers at 10 to 26 months of age, $45.3 \mathrm{~cm}^{2}$ and $1.03 \mathrm{~mm}$ at 11 to 17 months, and $49.0 \mathrm{~cm}^{2}$ and $1.94 \mathrm{~mm}$ at 18 to 24 months, respectively. Choy et al. (2011) reported $50.8 \mathrm{~cm}^{2}, 2.74 \mathrm{~mm}$, and 1.73 for LMA, BFT and MS in a sample of Hanwoo cows at 24 months or younger age. Compared with the results in this study, the values of Choy et al. (2011) were slightly greater for LMA and smaller for BFT and MS, and ranged within one standard deviation of the respective traits (Table 1).

\section{Heritabilities}

Heritability $\left(\mathrm{h}^{2}\right)$ estimates for LMA, BFT, and MS ultrasound measures in Hanwoo cows are shown in Table 2. The $\mathrm{h}^{2}$ estimates across all ages of the cows were $0.09,0.10$, and 0.08 for the respective traits. In the cow group of 18 to 22 months of age, the $\mathrm{h}^{2}$ estimates for LMA and BFT were 0.24 and 0.47 , which were the greatest among the four groups of cow age for the respective traits. Also, for the age group, the estimates of genetic variance were 6.79 and 0.83

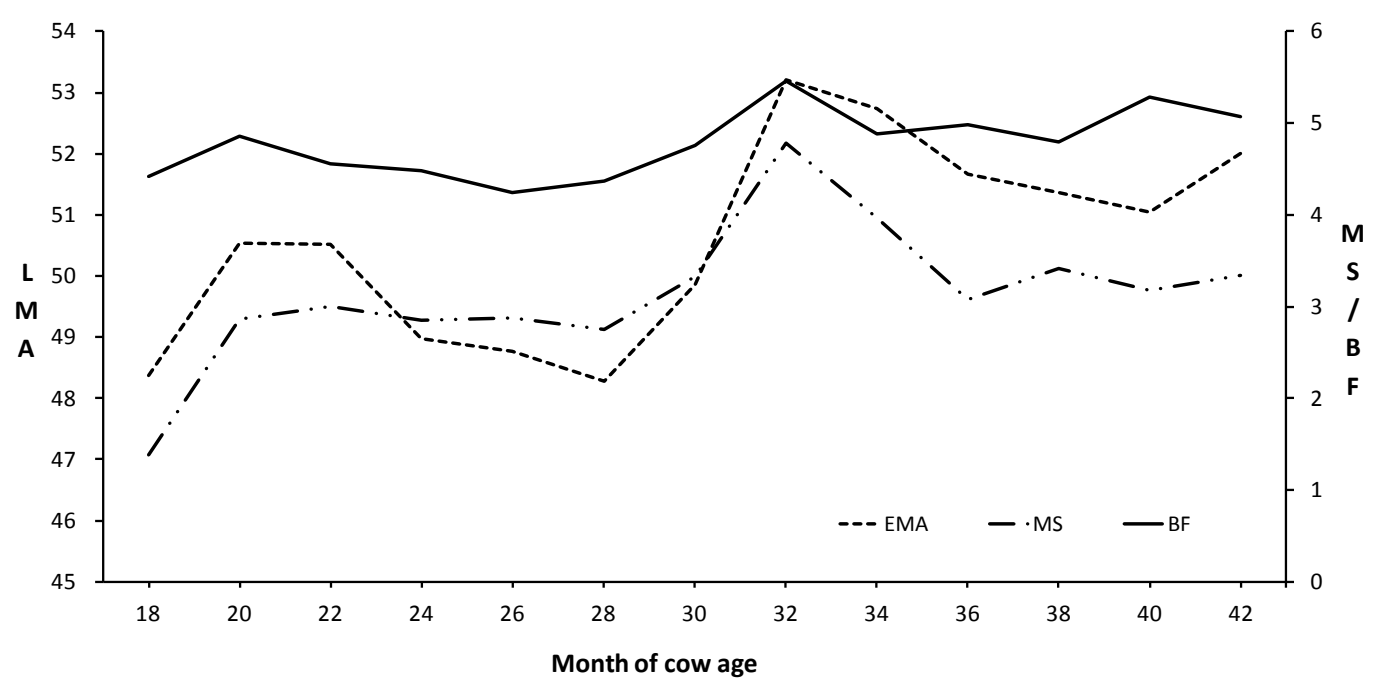

Figure 1. Average measurements of real-time ultrasound traits on month of age in Hanwoo cows. LMA = Longissimus dorsi muscle area $\left(\mathrm{cm}^{2}\right), \mathrm{BF}=$ Backfat thickness $(\mathrm{mm}), \mathrm{MS}=$ Marbling score. 
Table 2. Genetic variance $\left(\sigma_{\mathrm{a}}^{2}\right)$, residual variance $\left(\sigma_{\mathrm{e}}^{2}\right)$, and heritability $\left(\mathrm{h}^{2}\right)$ of real-time ultrasound traits in Hanwoo cows in different age groups

\begin{tabular}{lccccc}
\hline Trait & Age (mean of month) & $\mathrm{N}$ & $\sigma_{\mathrm{a}}{ }^{2}$ & $\sigma_{\mathrm{e}}{ }^{2}$ & $\mathrm{~h}^{2}$ \\
\hline LMA $\left(\mathrm{cm}^{2}\right)$ & $18-22(20.6)$ & 683 & $6.79 \pm 4.72$ & $21.8 \pm 4.00$ & $0.24 \pm 0.16$ \\
& $23-27(25.2)$ & 794 & $4.74 \pm 3.24$ & $30.6 \pm 3.14$ & $0.13 \pm 0.09$ \\
& $28-32(29.8)$ & 861 & $4.44 \pm 2.75$ & $24.5 \pm 2.56$ & $0.15 \pm 0.09$ \\
& $33-42(37.6)$ & 724 & $3.07 \pm 3.22$ & $29.8 \pm 3.19$ & $0.09 \pm 0.10$ \\
BFT (mm) & Overall (28.4) & 3,062 & $3.02 \pm 1.16$ & $30.3 \pm 1.21$ & $0.09 \pm 0.03$ \\
& $18-22(20.6)$ & 683 & $0.83 \pm 0.30$ & $0.92 \pm 0.24$ & $0.47 \pm 0.15$ \\
& $23-27(25.2)$ & 794 & $0.11 \pm 0.15$ & $1.94 \pm 0.17$ & $0.05 \pm 0.07$ \\
MS (1 to 9) & $28-32(29.8)$ & 761 & $0.12 \pm 0.14$ & $2.11 \pm 0.16$ & $0.05 \pm 0.06$ \\
& $33-42(37.6)$ & 3,062 & $0.25 \pm 0.29$ & $2.41 \pm 0.28$ & $0.09 \pm 0.11$ \\
& Overall (28.4) & 683 & $0.23 \pm 0.09$ & $2.05 \pm 0.09$ & $0.10 \pm 0.04$ \\
& $18-22(20.6)$ & 794 & $0.34 \pm 0.27$ & $1.64 \pm 0.24$ & $0.17 \pm 0.13$ \\
& $23-27(25.2)$ & 861 & $0.08 \pm 0.18$ & $2.73 \pm 0.22$ & $0.03 \pm 0.07$ \\
& $28-32(29.8)$ & 724 & $0.73 \pm 0.39$ & $2.69 \pm 0.34$ & $0.21 \pm 0.11$ \\
& $33-42(37.6)$ & 3,062 & $0.51 \pm 0.37$ & $3.27 \pm 0.37$ & $0.13 \pm 0.10$ \\
& Overall (28.4) & $0.26 \pm 0.11$ & $2.91 \pm 0.11$ & $0.08 \pm 0.03$ \\
\hline
\end{tabular}

LMA = Longissimus dorsi muscle area, BFT = Backfat thickness, MS = Marbling score ( $1=$ trace, $9=$ abundant $)$.

$\sigma_{\mathrm{a}}^{2}=$ Genetic variance, $\sigma_{\mathrm{e}}^{2}=$ Residual variance, $\mathrm{h}^{2}=$ Heritability.

(the greatest among the age groups), and those of residual variance were 21.8 and 0.93 (the smallest) for LMA and BFT, respectively (Table 2). The greatest heritability for MS $\left(\mathrm{h}^{2}=0.21\right)$ was obtained for the group of cows at 28 to 32 months old.

Shepard et al. (1996) reported that $\mathrm{h}^{2}$ estimates for LMA and BFT ultrasound measures were 0.12 and 0.50 in Angus bulls and heifers at 8 to 20 months of age. Stelzleni et al. (2002) reported 0.31, 0.26, and 0.16 in Brangus bulls ( $\mathrm{n}=$ $1,073)$ and heifers $(n=226)$ at 10.6 to 13.6 months of age for LMA, BFT, and intramuscular fat (\%), respectively. These $\mathrm{h}^{2}$ estimates were close to the estimates in the cow group of 18 to 22 months of age in this study (Table 2).

Moser et al. (1998) reported that, when ultrasound measurements were combined with progeny testing results, $\mathrm{h}^{2}$ estimates were 0.29 and 0.11 for ultrasound LMA and BFT in Brangus bulls and heifers of 10 to 14 months of age. Reverter et al. (2000) reported $\mathrm{h}^{2}$ estimates of $0.46,0.54$, and 0.47 in Angus heifers and 0.34, 0.27, and 0.12 in Hereford heifers for LMA, BFT and intramuscular fat (\%) ultrasound measures, respectively. Crew et al. (2004) reported $\mathrm{h}^{2}$ estimates of $0.51,0.69$, and 0.52 for the respective ultrasound traits in Simmental bulls and heifers of 12 months of age, when the data were combined with carcass traits by progeny testing. These results suggest that there is a tendency toward upward estimation of heritability, when data of ultrasound measurements are combined with carcass traits by progeny testing.

In Hanwoo, Koo (2007) reported that $\mathrm{h}^{2}$ estimates were $0.17,0.19$, and 0.13 for ultrasound LMA, BFT and MS, respectively, in a sample of cows $(\mathrm{N}=12,064)$ that were measured at 20 or older months of age from many Hanwoo breeding farms between 2001 and 2006. Yoon (2010) reported $0.15,0.39$, and 0.38 in Hanwoo cows $(\mathrm{N}=21,640)$, while Choy et al. (2011) reported 0.39, 0.48, and 0.13 for the respective ultrasound traits in Hanwoo cows $(\mathrm{N}=$ $6,629)$ with 15 or older months of age in Hanwoo breeding farms of Gyeonggi province. Our results showed that, in general, the $\mathrm{h}^{2}$ estimates across all age groups of cow were lower than the reports of Koo (2007), Yoon (2010) and Choy et al. (2011). However, when the group of cows between 18 and 22 months of age, the $\mathrm{h}^{2}$ estimates of LMA and BFT were greater than those in Koo (2007) and Yoon (2010), and for the cows at 28 to 32 months of age, the $h^{2}$ estimate of MS was greater than those in Koo (2007) and Choy et al. (2011) (Table 2).

In beef cattle of western breeds such as Angus or Simmental, measurement age of ultrasound traits was consistent, i.e. 12 months. However, ultrasound traits were measured in various ages in Hanwoo cows (Koo, 2007; Choy et al., 2011). Hassan et al. (2004) classified the ultrasound measures in six different age groups (8.1, 9.2, 10.6, 11.7, 12.3, and 13.4 months) in Angus bulls and heifers, and reported that heritability estimates ranged between 0.30 and 0.48 for LMA, for which $\mathrm{h}^{2}$ estimate was the greatest in 11.7 to 13.4 months of age. Pinheiro et al. (2011) also classified ages into several groups for LMA and BFT in Nelore bulls and heifers, and they reported that the $\mathrm{h}^{2}$ estimates were 0.46 and 0.26 for 11 to 17 months and 0.33 and 0.24 for 18 to 24 months of age, for the respective 
traits. Our results also showed different $\mathrm{h}^{2}$ estimates in various age groups (Table 2), suggesting that care must be taken when ultrasound measurements are applied to selection of cows for meat quality.

\section{Genetic and phenotype correlations}

Genetic $\left(r_{\mathrm{g}}\right)$ and phenotypic $\left(r_{\mathrm{p}}\right)$ correlations between the three ultrasound traits are described in Table 3. Across all the age groups of cows, the $r_{g}$ estimates were $0.43,-0.06$, and 0.21 , and the $r_{p}$ estimates were $0.35,0.34$, and 0.32 between LMA and BFT, LMA and MS, and BFT and MS, respectively. Since LMA and BFT increase with age and both BFT and MS are measures of adiposity, it is not surprising to get positive genetic and phenotypic relationship between the traits. When only the data from the Hanwoo cows at 18 to 22 months of age were used, the $r_{g}$ estimates were $0.40,0.02$, and 0.22 , and the $r_{p}$ estimates were $0.29,0.24$, and 0.24 for the respective pairs of traits. However, in an older age group (28 to 32 months), the $r_{g}$ and $r_{p}$ estimates were $0.05,-0.15$, and 0.38 , and $0.34,0.35$, and 0.35 , respectively. The different estimates of $r_{g}$ and $r_{p}$ between various cow age groups may be partly due to different estimates of genetic and environment components. In conclusion, our results suggest that, as cow age and pregnancy status may be important factors in influencing variability of ultrasound measures between cows, care should be taken in collection data of ultrasound measures and estimation and evaluation of genetic parameters in Hanwoo cows with different ages.

Table 3. Genetic (above the diagonal) and phenotypic (below the diagonal) correlations for real-time ultrasound measures in Hanwoo cows of different age groups

\begin{tabular}{llccc}
\hline $\begin{array}{c}\text { Age } \\
\text { (months) }\end{array}$ & Trait & LMA & BF & MS \\
\hline $18-22$ & LMA & - & $0.40 \pm 0.31$ & $0.02 \pm 0.52$ \\
& BF & $0.29 \pm 0.04$ & - & $0.22 \pm 0.37$ \\
& MS & $0.24 \pm 0.04$ & $0.24 \pm 0.04$ & - \\
$23-27$ & LMA & - & $-0.11 \pm 0.73$ & $-0.11 \pm 0.96$ \\
& BF & $0.36 \pm 0.03$ & - & $0.38 \pm 0.52$ \\
& MS & $0.31 \pm 0.04$ & $0.29 \pm 0.04$ & - \\
$28-32$ & LMA & - & $0.05 \pm 0.63$ & $-0.15 \pm 0.43$ \\
& BF & $0.34 \pm 0.03$ & - & $0.38 \pm 0.52$ \\
& MS & $0.35 \pm 0.04$ & $0.35 \pm 0.03$ & - \\
$33-42$ & LMA & - & $0.56 \pm 0.69$ & $0.38 \pm 0.58$ \\
& BF & $0.36 \pm 0.04$ & - & $0.09 \pm 0.64$ \\
& MS & $0.32 \pm 0.04$ & $0.27 \pm 0.04$ & - \\
Overall & LMA & - & $0.43 \pm 0.22$ & $-0.06 \pm 0.28$ \\
& BF & $0.35 \pm 0.02$ & - & $0.21 \pm 0.26$ \\
& MS & $0.34 \pm 0.02$ & $0.32 \pm 0.02$ & - \\
\hline
\end{tabular}

LMA $=$ Longissimus dorsi muscle area, $\mathrm{BF}=$ Backfat thickness, $\mathrm{MS}=$ Marbling score.

\section{ACKNOWLEDGEMENTS}

This research was financially supported by the Yeungnam University Research Grant 2013 and from the grant of Korea Institute of Planning and Evaluation for Technology of Food, Agriculture, Forestry and Fisheries, 2013.

\section{REFERENCES}

BIF. 1996. Minutes of the Beef Improvement Federation Real-time Ultrasound Committee Meeting. April 2, 1996. St. Joseph, MO. Choy, Y. H., J. K. Son, H. S. Kong, H. K. Lee, and K. D. Park. 2011. Estimation of genetic parameters for economic traits of Hanwoo cows using ultrasound. J. Anim. Sci. Technol. (Kor.) 53:505-509.

Crews Jr., D. H. and R. A. Kemp. 2002. Genetic evaluation of carcass yield using ultrasound measures on young replacement beef cattle. J. Anim. Sci. 80:1809-1818.

Crews Jr., D. H., E. J. Pollak, and R. L. Quaas. 2004. Evaluation of Simmental carcass EPD estimated using live and carcass data. J. Anim. Sci. 82:661-667.

Gilmour, A. R., B. R. Cullis, S. J. Welham, and R. Thompson. 1999. "NSW Agriculture Biometric Bulletin No. 3. ASREML Reference Manual". NSW Agriculture, Orange, NSW, Australia.

Gotoh, T., E. Albrecht, F. Teuscher, K. Kawabata, K. Sakashita, H. Iwamoto, and J. Wegner. 2009. Differences in muscle and fat accretion in Japanese Black and European cattle. Meat Sci. 82:300-308.

Hassen, A., D. E. Wilson, G. H. Rouse, and R. G. Tait Jr. 2004. Partitioning variances of growth in ultrasound longissimus muscle area measures in Angus bulls and heifers. J. Anim. Sci. 82:1272-1279.

Herring, W. O., L. A. Kriese, J. K. Bertrand, and J. Crouch. 1998. Comparison of four real-time ultrasound systems that predict intramuscular fat in beef cattle. J. Anim. Sci. 76:364-370.

Houghton, P. L. and L. M. Turlington. 1992. Application of ultrasound for feeding and finishing animals: A review. J. Anim. Sci. 70:930-941.

Howry, D. H. and W. R. Bliss. 1952. Ultrasonic visualization of soft tissue structures of the body. J. Lab. Clin. Med. 40:579592.

Koo, Y. M. 2007. Estimation of genetic correlation and parameter for ultrasound measurements and performance test data in Hanwoo cows (Korean cattle). Gyeongsang national university PhD paper.

Ludwig, G. D. 1950. The velocity of sound through tissues and the acoustic impedants of tissues. J. Acoust. Soc. Am. 22:862-866.

Moser, D. W., J. K. Bertrand, I. Misztal, L. A. Kriese, and L. L. Benyshek. 1998. Genetic parameter estimates for carcass and yearling ultrasound measurements in Brangus cattle. J. Anim. Sci. 76:2542-2548.

Perkins, T. L., R. D. Green, and K. E. Hamlin. 1992. Evaluation of ultrasonic estimates of carcass fat thickness and longissimus muscle area in beef cattle. J. Anim. Sci. 70:1002-1010.

Pinheiro, T. R., M. E. Z. Mercadante, L. G. Albuquerque, J. N. S. G. Cyrillo, and R. H. Branco. 2011. Phenotypic and genetic 
parameters compared during repeated measures of longissimus muscle area and subcutaneous fat thickness in Nelore cattle. Genet. Mol. Res. 10:2944-2952.

Reverter, A., D. J. Johnston, H. U. Graser, M. L. Wolcott, and W. H. Upton. 2000. Genetic analyses of live-animal ultrasound and abattoir carcass traits in Australian Angus and Hereford cattle. J. Anim. Sci. 78:1786-1795.

Roberts, A. J., S. I. Paisley, T. W. Geary, E. E. Grings, R. C. Waterman, and M. D. MacNeil. 2007. Effects of restricted feeding of beef heifers during the postweaning period on growth, efficiency, and ultrasound carcass characteristics. J. Anim. Sci. 85:2740-2745.

Roh, S. H., C. Y. Kim, Y. S. Won, C. J. Park, S. S. Lee, and J. G. Lee. 2010. Studies on genetic parameter estimation and sire selection to ultrasound measurement traits of Hanwoo. J. Anim. Sci. Technol. (Kor.) 52:1-8.

Shepard, H. H., R. D. Green, B. L. Golden, K. E. Hamlin, T. L. Perkins, and J. B. Diles. 1996. Genetic parameter estimates of live animal ultrasonic measures of retail yield indicators in yearling breeding cattle. J. Anim. Sci. 74:761-768.

Stelzleni, A. M., T. L. Perkins, A. H. Brown Jr., F. W. Pohlman, Z. B. Johnson, and B. A. Sandelin. 2002. Genetic parameter estimates of yearling live animal ultrasonic measurements in Brangus cattle. J. Anim. Sci. 80:3150-3153.
Temple, R. S., H. H. Stonaker, D. Howry, G. Posakony, and M. H. Hazeleus. 1956. Ultrasonic and conductivity methods for estimating fat thickness in live cattle. Proc. West. Sect. Am. Soc. Him. Prod. 7:4TI.

Waldner, D. N., M. E. Dikeman, R. R. Schalles, W. G. Olson, P. L. Houghton, J. A. Unruh, and L. R. Corah. 1992. Validation of real-time ultrasound technology for predicting fat thicknesses, longissimus muscle areas, and composition of Brangus bulls from 4 months to 2 years of age. J. Anim. Sci. 70:3044-3054.

Yokoo, M. J., L. G. Albuquerque, R. B. Lôbo, L. A. F. Bezerra, F. R. C. Araujo, J. A. V. Silva, and R. D. Sainz. 2008. Genetic and environmental factors affecting ultrasound measures of longissimus muscle area and backfat thickness in Nelore cattle. Livest. Sci. 117:147-154.

Yoon, W. J. 2010. Study on genetic improvement for meat quality of Hanwoo cows using ultrasonic measurements. Hankyong National University. PhD dissertation.

Zhou, G. H., L. Liu, X. L. Xiu, H. M. Jian, L. Z. Wang, B. Z. Sun, and B. S. Tong. 2001. Productivity and carcass characteristics of pure and crossbred Chinese Yellow Cattle. Meat Sci. 58:359-362. 